\title{
A REALIDADE E SEU CONCEITO: COMENTÁRIOS SOBRE A CRÍTICA AO "SEQUESTRO DA SUBJETIVIDADE"
}

\author{
José Henrique de Faria ${ }^{2}$
}

http://dx.doi.org/10.1590/1413-2311.239.90276

\begin{abstract}
RESUMO
Este artigo consiste em comentários sobre a crítica ao conceito de sequestro da subjetividade proposto por Deise Luiza Ferraz em "Sequestro da Subjetividade: revisitando o conceito e capturando o real". Neste artigo, argumento a favor do conceito de controle e sequestro da subjetividade, valorizando as críticas de Ferraz, naquilo que este conceito tem de essencial. Especialmente porque entendo que o propósito dos conceitos de controle e de sequestro da subjetividade foi exatamente o de primeiramente "capturar o real" em sua dimensão imediata, que se me apresentou à observação primeira (em uma aproximação precária) em sua aparência fenomênica, para desenvolvê-lo para além de sua pseudoconcreticidade. Faço os comentários a partir de duas questões: (i) conceitos são desenvolvidos à medida que as práticas se modificam historicamente e à medida que o conhecimento sobre o objeto se aprofunda com a evolução da ciência: (ii) toda pesquisa tem como projeto a condição de esclarecer, inovar, acrescentar, surpreender, provocar e transformar.
\end{abstract}

Palavras-Chave: Controle da subjetividade. Sequestro da subjetividade. Processo de trabalho. Gestão da produção. Marxismo. Método.

\footnotetext{
${ }^{1}$ Recebido em 03/02/2019; aprovado em 04/03/2019.

${ }^{2}$ Universidade Federal do Paraná (UFPR) - Programa de Pós-Graduação em Administração (PPGADM) e Professor Visitante na Universidade Tecnológica Federal do Paraná - Programa de Pós-Graduação em Administração (PPGA); Curitiba - PR (Brasil) - jhfaria@gmail.com
} 


\title{
REALITY AND ITS CONCEPT: COMMENTS ON THE CRITIQUE OF THE "KIDNAPPING OF SUBJECTIVITY'
}

\begin{abstract}
This article consists in a commentary about the critique of the concept of kidnapping of subjectivity by Deize Luiza Ferraz in "Kidnapping of subjectivity: revisiting the concept and capturing the real." In this article I argument on the defense of the concept of kidnapping and control of subjectivity just in what this concept is essential, considering the critique of Ferraz. Especially because I understand that the purpose of the concepts of control and of kidnapping of subjectivity was exactly the first "capture of the real" in its immediate dimension, which introduced me to the first observation (in a precarious approach) in its appearance, to develop it beyond its pseudoconcreticity. I do this commentary from two issues: (i) concepts are developed as the reality changes historically and as the knowledge about the object deepens with the evolution of Science: (ii) all research should contain the condition of to clarify, innovate, add, surprise, provoke and transform.
\end{abstract}

Keywords: Control of subjectivity. Kidnapping of subjectivity. Work process. Production management. Marxism. Method.

\section{LA REALIDAD Y SU CONCEPTO: COMENTARIOS SOBRE LA CRÍTICA AL 'SECUESTRO DE LA SUBJETIVIDAD'}

\section{RESUMEN}

Este artículo consiste en comentarios sobre la crítica al concepto de secuestro de la subjetividad propuesto por Deise Luiza Ferraz en "Secuestro de la subjetividad: revisitando el concept y capturando lo real". En este artículo argumento a favor del concepto de control y secuestro de la subjetividad, valorizando las críticas de Ferraz en lo que el concepto tiene de esencial. Especialmente porque entiendo que el propósito de los conceptos de control y de secuestro de la subjetividad fue exactamente el de primero "capturar lo real" en su dimensión inmediata, que se me presentó a la observación primera (en una aproximación precaria) en su apariencia fenoménica, para desarrollarlo más ala de su pseudo-concreticidad. Hago los 
comentarios a partir de dos cuestiones: (i) conceptos son desarrollados en la medida en que las practicas cambian históricamente y en la medida en que el conocimiento sobre el objeto se profundiza con la evolución de la ciencia; (ii) toda investigación tiene como proyecto la condición de aclarar, innovar, acrecentar, sorprender, provocar y transformar.

Palabras clave: Control de la subjetividad. Secuestro de la subjetividad. Proceso de trabajo. Gestión de la producción. Marxismo. Método.

A dialética, afirma Kosik (1976, p. 9-10),

Trata da "coisa em si". Mas a "coisa em si" não se manifesta imediatamente ao homem. Para chegar à sua compreensão, é necessário fazer não só um certo esforço, mas também um détour. Por este motivo o pensamento dialético distingue entre representação e conceito da coisa, com isso não pretendendo apenas distinguir duas formas e dois graus de conhecimento da realidade, mas especialmente e sobretudo duas qualidades da práxis humana. A atitude primordial e imediata do homem, em face da realidade, não é a de um abstrato sujeito cognoscente, de uma mente pensante que examina a realidade especulativamente, porém a de um ser que age objetiva e praticamente, de um indivíduo histórico que exerce a sua atividade prática no trato com a natureza e com os outros homens, tendo em vista a consecução dos próprios fins e interesses, dentro de determinado conjunto de relações sociais. Portanto, a realidade não se apresenta aos homens, à primeira vista, sob o aspecto de um objeto que cumpre intuir, analisar e compreender teoricamente, cujo polo oposto e complementar seja justamente o abstrato sujeito cognoscente, que existe fora do mundo e apartado do mundo; apresenta-se como o campo em que se exercita a sua atividade prático-sensível, sobre cujo fundamento surgirá a imediata intuição prática da realidade. (...) "a existência real" e as formas fenomênicas da realidade - que se reproduzem imediatamente na mente daqueles que realizam uma determinada práxis histórica, como conjunto de representações ou categorias do "pensamento comum" (que apenas 
por "hábito bárbaro" são consideradas conceitos) - são diferentes e muitas vezes absolutamente contraditórias com a lei do fenômeno, com a estrutura da coisa e, portanto, com o seu núcleo interno essencial e seu conceito correspondente.

Neste artigo, que se trata de um comentário ao texto "Sequestro da subjetividade: revisitando o conceito e capturando o real" de autoria de Deise Luiza Ferraz, que antecede esta réplica, utilizarei, excepcionalmente, a primeira pessoa do singular, considerando que esse texto faz uma crítica ao conceito de sequestro da subjetividade, desenvolvido por mim (FARIA, 2004) e empregado também em um estudo publicado por mim e por Francis K. Meneghetti (FARIA; MENEGHETTI, 2007). Não vou, igualmente, indicar referências bibliográficas além daquelas necessárias. Eu poderia tomar ponto por ponto as considerações de Ferraz sobre as quais tenho divergências, mas entendo que isto seria uma forma de pedantismo intelectual. Desta forma, decidi argumentar a favor do conceito de controle e sequestro da subjetividade, valorizando as críticas de Ferraz, naquilo que este conceito tem de essencial. Especialmente porque entendo que o propósito dos conceitos de controle e de sequestro da subjetividade foi exatamente o de primeiramente "capturar o real" em sua dimensão imediata, que se me apresentou à observação primeira (em uma aproximação precária) em sua aparência fenomênica, para desenvolvê-lo para além de sua pseudoconcreticidade.

Há duas questões que necessitam ser colocadas de pronto com relação às análises de Deise Ferraz: (i) conceitos são desenvolvidos à medida que as práticas se modificam historicamente e à medida que o conhecimento sobre o objeto se aprofunda com a evolução da ciência: (ii) toda pesquisa tem como projeto a condição de esclarecer, inovar, acrescentar, surpreender, provocar e transformar. A reprodução esclarecedora da pesquisa, portanto, não tem o mesmo estatuto que a sua forma de reprodução simples, sendo esta sua forma estéril.

Sobre o primeiro ponto, colocar em confronto uma disputa conceitual em que a referência histórica de um se encontra distante da referência do outro, é uma forma de trazer para o terreno da pura abstração conceitual aquilo que pertence ao terreno da representação concreta. Será possível tomar os estudos de Marx, realizados em determinado estágio de desenvolvimento das forças produtivas, para a partir dele estruturar a crítica à uma relação concreta que se organiza em outro estágio? A compreensão sobre a subjetividade, restrita à filosofia nos idos de 1800, evoluiu com a ciência, especialmente com o desenvolvimento da psicologia social, colocando em evidência elementos concretos que se encontravam 
abstraídos nos conceitos de "espírito" (por exemplo, em Hegel: A Fenomenologia do Espírito).

Sobre o segundo ponto, a reprodução dedicada da pesquisa, em que o pesquisador avança sobre a base teórica disponível para, tendo por primazia a realidade, promover avanços esclarecedores, deve se impor sobre a simples reprodução conceitual, que é sua face estéril. Os processos de controle sobre as relações de trabalho foram sendo modificados conforme o desenvolvimento das forças produtivas. Tanto a incorporação de tecnologias físicas quanto de tecnologias de gestão fizeram alterar as formas singulares da gestão do trabalho e da produção sob o capital. Ainda que a subjetividade sempre estivesse contida nas relações de trabalho, os investimentos do capital em seu controle são mais recentes, como argumentarei adiante.

No início do texto, Ferraz indica que “[...] seguindo os ensinamentos de Marx (2013), o processo de investigação do real inicia-se pelo que é mais imediato, o que se apresenta a observação, pela aparência do fenômeno. Porém, esse é somente o início de um processo que tem por objetivo apropriar-se idealmente das inter-relações entre os aspectos concretos do fenômeno - das relações entre os elementos constitutivos do fenômeno que o faz ser o que é. Esse movimento que parte do que se dá a observação rumo à apreensão de suas múltiplas determinações, precisa, segundo Marx, ser distinguido do processo de exposição". Em seguida: “[...] a descrição do que é denominado sequestro da subjetividade é a aparência do fenômeno, na essência trata-se da produção de uma subjetividade correspondente ao modo de produção metabólico do capital e de sua apropriação privada". Exatamente aí se encontra a raiz dos problemas que sustentam o argumento crítico de Ferraz. O que considero, explicitamente, é que o sequestro é a forma imediata mais desenvolvida do controle da subjetividade, sendo necessário apropriar-se historicamente dos seus determinantes, ou seja, trata-se de uma análise que procura seguir os "ensinamentos de Marx". Ferraz, contudo, ao fazer a crítica do que chama de aparência (sequestro da subjetividade), opondo-lhe a essência (a produção da subjetividade e sua apropriação privada), toma todo o argumento apresentado por mim e por Meneghetti como necessariamente inscrito no campo da aparência, quando o mesmo avança sobre a essência prática, sobre a realidade objetivada no interior da gestão capitalista do processo de trabalho. Em outras palavras, quando propus o conceito iniciei pelo que é imediato, pelo controle do processo de trabalho pelo capital, não apenas em sua execução e no uso de instrumentos, mas igualmente nas tecnologias, cada vez mais sofisticadas, de gestão. Estou de acordo que a subjetividade é uma produção social apropriada privadamente: é exatamente esta apropriação privada que foi objeto do conceito proposto e 
que se encontra no estudo realizado por Meneghetti e por mim. Concordo que esta questão não resta clara no texto examinado por Ferraz, pois era, para nós (Meneghetti e eu) um já dado.

Assim, de início, é oportuno expor rapidamente a "história do conceito" de sequestro da subjetividade. Ao desenvolver a Teoria Crítica do Controle (FARIA, 2004, Volume III), tendo examinado a própria história do desenvolvimento das ideologias de gestão, desde Taylor-Fayol-Ford até a o Toyotismo (produção flexível ou enxuta), propus a tese de que a teoria da administração, rigorosamente, é uma teoria sobre a prática do controle (daí a teoria crítica do controle) ou uma ideologia do poder do Capital, na esteira da proposta de Tragtenberg. Em outros termos, tal teoria é ao mesmo tempo o reasseguramento do arcabouço tanto da produção quanto da reprodução da lógica da acumulação capitalista no âmbito da gestão do processo de trabalho em unidades produtivas.

Como se sabe, todo processo de produção contém elementos objetivos e subjetivos. Objetivos, desde os instrumentos e meios de produção, as forças produtivas materiais, a matéria prima, energia, insumos, etc. até a objetivação do próprio resultado: a mercadoria. Subjetivos, desde as condições físicas (habilidade, destreza), o conhecimento (tácito ou partilhado, individual ou social), até as condições psicológicas ou emocionais (vínculo com a organização, comprometimento, identificação com os objetivos, etc.). Os elementos subjetivos se encontram em plena atividade durante o processo de transformação ou de produção. Este fenômeno não depende de um modo específico de produção, encontrando em cada um sua especificidade. Entretanto, é no sistema de capital que o controle sobre o processo de trabalho encontra sua forma mais desenvolvida com seus diversos mecanismos de realização. No modo capitalista de produção, o processo de transformação ou produção de mercadorias se encontra sob controle do capital, ou seja, o capital controla todo o processo de trabalho e seus operadores, os trabalhadores.

Assim, desde que o modo capitalista de produção se tornou dominante, o controle sobre o processo de produção de mercadorias e, claro, sobre o processo de trabalho produtivo sob o capital, torna-se fundamental para garantir a acumulação, simples ou ampliada. Não se trata apenas do controle sobre o aparato operativo do trabalho, mas fundamentalmente sobre todo o processo. As formas de controle evoluíram dos modos mecânicos (velocidade das esteiras, relógios, etc.) para os analógicos, informacionais, a laser e digitais. Os mecanismos de controle da subjetividade também foram sendo aperfeiçoados à medida que a organização do trabalho igualmente se modificava, desde do controle físico de tempos e movimentos (na Organização Científica do Trabalho) até as formas mais sofisticadas de controle da 
subjetividade (na Produção Flexível). O sequestro da subjetividade é, nesta perspectiva histórica, a forma mais desenvolvida de controle da subjetividade. Portanto, controle da subjetividade não é o mesmo que sequestro da subjetividade, embora o sequestro seja uma forma desenvolvida de controle.

Afirmar que não há sequestro sob o sistema de capital porque não há liberdade é equivalente a sugerir que não há transformação possível e que não há nas relações sociais nada além do capital. A liberdade, condição fundante da sociedade burguesa, constitui, dialeticamente, tanto a base da compra e venda da força de trabalho livre (e de sua submissão), como a base de sua resistência política, social e econômica. A constituição da subjetividade não é a constituição de um padrão ou de um modo humano de ser e, portanto, não pode ser confrontada com a existência ou a ausência de liberdade social, política, econômica ou jurídica. Não são correlatos causais.

Tenho dedicado minhas pesquisas, desde 1978, ao tema do poder e do controle do processo de trabalho na gestão das unidades produtivas capitalistas. O controle da subjetividade encetado pelo capital não é a aparência, mas exatamente a forma essencial de manifestação de seu sociometabolismo no estágio mais desenvolvido da gestão da produção e da apropriação privada dos resultados. O controle da subjetividade no processo de trabalho subsumido ao capital é a materialização do poder do capital enquanto proprietário privado dos instrumentos de trabalho, dos meios de produção e dos resultados do processo de trabalho (mercadorias). Trata-se de um poder de classe. O concreto que se manifesta de imediato no processo de trabalho e, sobre ele, nos mecanismos de controle aplicados pela gestão capitalista é uma das formas de exercício deste poder na esfera da produção (registro, apenas, que este exercício se encontra nas esferas da circulação de mercadorias, de capital e em toda a superestrutura política, institucional, cultural, ideológica e jurídica).

Pesquisas realizadas desde 1978 nas fábricas (FARIA, 1985; 1985b; 1992), indicam que no modelo fordista os mecanismos de controle eram fundamentalmente autoritários, físicos e emocionais (violência psicológica). Neste modelo, a característica principal era a linha de produção, com um supervisor de linha (um mestre) vigiando um segmento da linha. O controle de qualidade era randômico e estatístico. Não havia equipes de trabalho ou grupos parcialmente autônomos de trabalho. Os operários eram distribuídos ao longo da linha de produção.

A subjetividade estava ausente no modelo fordista de produção? Ou no taylorismo? Evidente que não. O capital não se ocupava, nestes modelos, com a subjetividade? Evidente que não, como mostrei à exaustão (FARIA, 2004, Volume II). A questão é se nestes modelos 
a gestão do processo de trabalho e da produção já estavam contidos procedimentos explícitos específicos dedicados ao controle da subjetividade. Há uma introdução rasa ao controle da subjetividade nos estudos de Elton Mayo e Roethlisberger sobre a "organização informal". No desenvolvimento das teorias capitalistas de gestão, contudo, a subjetividade passa a ser objeto de atenção apenas quando, ainda em sua forma simples, às teorias de gestão são incorporadas as teorias behavioristas da psicologia. Desde este período histórico do uso das teorias behavioristas na gestão das unidades produtivas até os dias atuais, as práticas de gestão foram, cada vez mais e em consonância com o desenvolvimento de tecnologias físicas que alteraram o próprio processo de trabalho, fazendo uso de estratégias de controle mais eficientes da subjetividade no trabalho. E o fizeram para além do behaviorismo.

Vou me permitir inserir, aqui, uma parte de um texto (FARIA, 2017, item 1.6.2.).

Mesmo que o Capital se aproprie da força de trabalho (em sua constituição objetiva e subjetiva), não a controla imediata e automaticamente. Há, de pronto, uma mediação realizada pela propriedade privada dos meios de produção (meios e objetos de trabalho), que se materializa na definição, pelo Capital, sobre o que, quanto, como e onde produzir. A mediação, pelo Capital, entre a força produtiva de trabalho e seu uso como capital (variável) indica que há um empenho, pelo Capital, em estabelecer procedimentos que visem extrair a máxima utilidade da força de trabalho comprada. O controle sobre o processo de trabalho, emblematicamente exposto na chamada Organização Científica do Trabalho, aparece como "função" do Capital assim que este o desenvolve. Se a apropriação das capacidades objetiva e subjetiva de trabalho fosse imediatamente controlada pelo Capital, nenhum esforço teria sido feito pela teoria gerencialista em desenvolver as forças produtivas, especialmente o saber técnico e científico aplicado ao processo de trabalho. Assim como a capacidade física não está total e imediatamente disponível e sob controle, também não o está a condição subjetiva, essa muito menos suscetível de avaliação quantitativa ou mesmo qualitativa pelo Capital.

O controle da subjetividade é uma prática do Capital desde que este se organiza como modo de produção. O que o Capital controla não é a subjetividade em si mesma, abstrata, mas aqueles seus elementos constitutivos que, direta e/ou indiretamente, participam de forma 
ativa no processo de produção. Sua forma mais desenvolvida se encontra no modelo flexível de produção e é partindo desta forma que se pode compreender sua evolução desde seu estágio mais simples. No chamado modelo toyotista (produção enxuta ou flexível), a organização do trabalho se altera. Ao pesquisar a instalação de uma fábrica (unidade fabril) com modelo flexível de produção em uma indústria de eletrodomésticos, ao mesmo tempo em que esta mantinha uma fábrica (unidade fabril) operando no modelo fordista de linha de montagem, tornou-se possível verificar que a organização do trabalho exigia, tendo em vista a reorganização produtiva e o emprego de tecnologias físicas de base microeletrônicas, a substituição da linha de montagem por ilhas de produção (ou de montagem). Aqui aparecem as equipes de trabalho, os grupos participativos, o controle de qualidade por meio informacional, o controle de estoques assistidos por computador (just in time, kanban etc.), a criação de Grupos Semiautônomos, etc. Às alterações na base física corresponderam alterações nos programas de gestão e controle.

Pesquisas realizadas por mim em 1988 e 1989 mostram a relação entre tecnologias físicas e tecnologias de gestão no desenvolvimento dos processos de gestão do trabalho nas fábricas (FARIA, 1992). Ainda que tivesse constatado as diferenças na gestão do processo de trabalho entre as unidades produtivas que, então, estavam migrando para o toyotismo e aquelas que eu havia pesquisado entre 1978 e 1985, tipicamente fordistas, não estava clara a correspondente evolução do controle sobre a subjetividade. Esse entendimento foi se tornando mais evidente com as pesquisas realizadas no âmbito do Grupo de Pesquisa Economia Política do Poder em Estudos Organizacionais - EPPEO.

O controle sobre o processo de trabalho, especialmente o da subjetividade, já é uma forma de desenvolvimento da gestão capitalista de trabalho. Para rastrear esse nexo interno do processo de controle de forma detalhada, não bastou tomar o processo de trabalho e tampouco o controle sobre ele em si mesmos. Foi preciso chegar à sua forma mais desenvolvida (o controle da subjetividade) para compreender o processo que a fez ser, em seu desenvolvimento, não apenas um controle objetivo, mas também subjetivo. Portanto, o concreto imediato não se encontra nas relações de controle, pois estas já se constituem em uma forma mediada de investigação, que supera a aparência reificada. Ferraz afirma que "se não houver a exteriorização da subjetividade não há relação social. A exteriorização da subjetividade é condição sine qua non da própria humanidade”. Exato. Porém, argumento que a exteriorização da subjetividade não é diretamente seu controle e sequestro; ao contrário, há um investimento do capital neste processo. Daí que a expressão "doação forçada" remete às 
sutilezas do sistema de controle e do próprio sequestro e não a uma imposição explicitamente coercitiva.

Ao pesquisar as relações de trabalho, particularmente com os decasséguis, em uma fábrica japonesa, o meu objetivo e de Meneghetti (FARIA; MENEGHETTI, 2007) era o de investigar o que levava estes trabalhadores (com remunerações mais baixas, com piores condições de trabalho e com péssima qualidade de vida), a estabelecerem uma identificação emocional com as empresas. Eram trabalhadores temporários, já que permaneciam alguns anos no Japão para "formar uma poupança" e retornar ao Brasil. Eram trabalhadores tratados de forma diferenciada em relação aos trabalhadores japoneses. Ao analisar os resultados dos dados, percebemos que a empresa desenvolvia um "Programa de Sedução", que tinha por finalidade "docilizar os corpos" (na concepção teórica foucaultiana, mesmo, mas não segundo sua ontologia) e mentes dos trabalhadores. Neste sentido, os conceitos de controle e sequestro da subjetividade pareceram adequados para a análise. No texto de Ferraz, o conceito aparece como se tivesse tratando de uma singularidade, de uma aparência. Daí sua crítica. Posso concordar totalmente com os argumentos quanto à questão ontológica, epistemológica e metodológica, pois o texto original publicado em 2007 dá margem a esta crítica. Mais ainda, posso admitir que a exposição do sequestro da subjetividade em tipos ou formas, parece equivocada. Foram as críticas a essa concepção, realizadas em debates com a própria Deise Ferraz e com outros pesquisadores, que me levaram a considerar que não se tratam de formas de sequestro, mas de determinados elementos da subjetividade que eram alvos do sequestro. Embora eu já tenha feito um aprofundamento no conceito superando sua versão original, exposto em outra publicação (FARIA, 2017), é preciso considerar que o conceito de subjetividade conhecido é o que foi publicado em 2007.

Em síntese, o investimento do capital sobre o controle do processo de trabalho, em sua aparência fenomênica, repousa em elementos objetivos, expressos em resultados mensuráveis: aumento da produtividade e da taxa de acumulação (simples ou ampliada). No entanto, por detrás das aparências, evidencia-se um processo de controle não apenas sobre os elementos objetivos do processo de trabalho, como igualmente sobre a subjetividade do trabalhador no e fora do processo de trabalho. Partindo da forma mais desenvolvida do controle da subjetividade pelas unidades produtivas em suas práticas de monopólio da sedução, materializada no sequestro da subjetividade, pode-se compreender como este processo se desenvolveu historicamente.

Retomo, para fundamentar, o argumento. Quando o trabalhador vende sua força de trabalho ao capital, vende suas condições físicas e mentais (emocionais, psicológicas) que o 
constituem como sujeito determinado socialmente. O capital, uma vez apropriada a força de trabalho, coloca-a para produzir mercadorias. Este processo exige, do capital, que este exerça um controle e uma vigilância permanente sobre a força de trabalho tendo em vista a produção de valor e a acumulação simples e/ou ampliada. Assim como o processo de trabalho se modifica à medida que se desenvolvem as forças produtivas, os mecanismos de controle da gestão deste processo também se modificam. Por que o capital controla a subjetividade se já a tem quando compra a mercadoria força de trabalho? Porque não basta ao capital adquirir a força de trabalho. O capital investe em seu controle para obter a máxima produtividade possível, ou seja, para subsumi-la formal e realmente através da introdução e utilização de tecnologias físicas e de gestão. Trata-se de uma relação econômica (de propriedade dos meios de produção) e ao mesmo tempo social, jurídico-política e ideológica.

Como já exposto exaustivamente (FARIA, 2004. Vol. II), o desenvolvimento das abordagens teóricas em gestão constitui um campo apropriado para o estudo do investimento feito pelo capital sobre o controle da subjetividade dos trabalhadores, embora este investimento seja formalmente negado. As abordagens teóricas colocam em evidência a forma fenomênica dos seus objetos, apresentando-os em sua aparência. Sem embargo, embora o taylorismo seja conhecido pela concepção de tempos e movimentos, em que a economia dos movimentos representa a intensificação do tempo dedicado ao trabalho, Taylor introduz em seus princípios de gerência científica a identificação subjetiva do trabalho com o capital (princípio da identidade de interesses) e a referência idealista do trabalhador padrão, cujo desempenho deveria servir de modelo aos demais trabalhadores (o trabalhador de tipo ideal). Na mesma época, ou seja, entre 1910 e 1940, Henry Ford, em diversos depoimentos, explicita a lógica do controle social da subjetividade através de programas de acompanhamento da vida privada de seus trabalhadores, da criação física de uma comunidade de trabalhadores afrodescendentes com o apoio de organizações religiosas. Ainda que o controle da subjetividade esteja no alvo destas propostas, sua efetividade é frágil, como o demonstram os movimentos sindicais de resistência.

As pesquisas na fábrica de relés de telefone na unidade de Hawthorne, em Chicago, conduzidas por Elton Mayo, Roethlisberger e outros pesquisadores justamente na época da Grande Depressão (1929-1933), indicam claramente os elementos subjetivos presentes nas relações e no processo de trabalho em termos de aumento da produtividade. O que os pesquisadores denominaram de "organização informal” não é, senão, o conjunto das relações intersubjetivas entre as operárias do grupo de controle. Estas “descobertas" deram origem ao que se convencionou chamar de Escola de Relações Humanas, desencadeando outras 
pesquisas com o objetivo de investigar a importância da subjetividade na gestão do processo de trabalho.

De fato, a subjetividade passa a ser um tema recorrente nas pesquisas e na literatura em gestão, porém jamais com a admissão explícita de que se tratava de um elemento a ser controlado. A hierarquia das necessidades de Maslow e a chamada Teoria Y de McGregor expõem a necessidade de controle sobre a subjetividade do trabalhador: o primeiro reduzindo a categoria dos desejos e estabelecendo etapas de sua satisfação; o segundo, sugerindo que o perfil do trabalhador não é aquele do taylorismo, mas suscetível de cessão a uma gestão humanizada. A incorporação das teorias behavioristas da psicologia nos estudos da gestão das unidades produtivas tornou mais explícito ainda o investimento no controle da subjetividade do trabalhador, embora de forma dissimulada: a racionalidade administrativa sob viés do comportamento humano (Simon e March); o modelo participativo de gestão (Likert); o contrato psicológico (Argyris); o equilíbrio entre interesses humanos e de produção em um grid gerencial (Blake e Mouton).

A introdução da concepção de controle da qualidade na gestão, atribuída ao toyotismo, não apenas representou a retomada do modelo fordista, agora em uma base microeletrônica, de redução do retrabalho e do tempo morto e da intensificação do trabalho com aumento da produtividade: representou um ataque à subjetividade através da constituição de equipes de trabalhos colaborativas e igualmente competitivas, integradas aos objetivos do capital. Aqui se deu o início prático do modelo contemporâneo de gestão centrado no monopólio da sedução pela organização produtiva: a fábrica não é mais apenas o local de trabalho, mas também de "convivência social", de atividades de lazer, de ecumenismo e de vida familiar. Programas de gestão de competências, clima e cultura, meritocracia, avaliação de desempenho, gestão do conhecimento, fidelização, adesão ao DNA empresarial, desenvolvimento de lideranças, entre outros, tratam de seduzir os trabalhadores em torno da crença em um ideal, valendo-se da condição humana de estabelecer relações afetivas de trabalho necessárias à manutenção de sua saúde física e emocional. Esta é a fase em que o controle da subjetividade avança para a prática do sequestro.

A gestão das fábricas no início da revolução industrial, embora objetivasse a produção de valor e a acumulação simples e/ou ampliada do capital, não se organiza nas unidades produtivas modernas da mesma forma. Desde as primeiras fábricas até as atuais unidades produtivas robotizadas, o processo de trabalho e suas formas de gestão se modificaram. Esta é uma realidade histórica concreta. Para entender este processo de evolução é necessário, seguindo o método, tomar o imediato atual e tensioná-lo para apreendê-lo como concreto 
histórico. O controle da subjetividade insere-se no processo de alienação e estranhamento ao qual se referia Marx, porém de forma mais desenvolvida do que aquele que deu origem ao conceito marxista.

De fato, tal processo de controle da subjetividade não supera o da auto-alienação e auto estranhamento do trabalhador a que se referia Marx, mas decididamente é mais do que isso. Trata-se de um ataque planejado e deliberado do capital sobre a subjetividade do trabalhador, apropriando-se do conhecimento desenvolvido nas ciências humanas e sociais (especialmente a psicologia e a sociologia clínica) visando aliená-lo em razão do projeto de expansão sociometabólica do capital. É uma alienação imposta pelo capital ao trabalhador valendo-se da subjetividade que o constitui como sujeito, segundo mecanismos tanto universais como particulares e singulares.

Neste sentido, portanto, os conceitos de controle e de sequestro da subjetividade não tratam da realidade imediata das relações trabalhistas sob a ótica do indivíduo. Ao contrário, tratam da estrutura do controle sobre o processo coletivo de trabalho exatamente nas formas que este controle nega, ou seja, para além das aparências fenomênicas. Ao afirmar a necessidade de distinção entre o "modo de exposição segundo sua forma" e o "modo de investigação" (que se apropria da matéria em detalhes, analisando suas "diversas formas de desenvolvimento" e rastreando seu "nexo interno"), Marx indica que apenas após a investigação é que se pode "expor adequadamente o movimento". Se tal exposição é bemsucedida e se "a vida da matéria" é então refletida idealmente, o "observador pode ter a impressão de se encontrar diante de uma construção a priori”, ou seja, a descrição concreta do objeto em sua manifestação prática não é seu conceito: o conceito da coisa não é a coisa em si mesma.

Talvez a exposição do conceito de sequestro da subjetividade, no texto analisado por Ferraz, não faça justiça ao seu desenvolvimento: mas isso é responsabilidade dos autores (Faria e Meneghetti) e não dos críticos. Portanto, pode-se considerar a crítica ao conceito de sequestro da subjetividade totalmente pertinente, não obstante (i) a mesma não faça uma adequada distinção entre controle e sequestro da subjetividade, (ii) exagere na remessa à leitura de Marx, cujas análises datam de mais de 150 anos dos fatos atualmente estudados (as práticas e o conhecimento sobre a gestão das unidades produtivas eram mais simples historicamente); (iii) equivoque-se quanto à dimensão epistemológica e a sobreponha a uma ideologia burguesa.

O Capital se constitui objetivamente na instância econômica, instituindo-se como modo dominante de produção nos planos jurídico, político, cultural e ideológico. Sua força 
avassaladora de perpetuação encontra-se também incrustada na instância psicossocial com o suporte direto e indireto do desenvolvimento das ciências, inclusive as humanas, sociais e sociais aplicadas. Esclarecer como o desenvolvimento das forças produtivas invadem a produção da subjetividade social e desvendar as práticas de seu controle e sequestro é uma tarefa histórica.

O conceito de sequestro da subjetividade teve e tem ainda muito mais repercussão e impacto na área de estudos da gestão e das organizações do que eu poderia supor quando de sua primeira publicização e certamente merece ser mais adequadamente exposto. Neste sentido, o compromisso mais relevante no âmbito acadêmico é a crítica consistente, visando o desenvolvimento das teorias. É o que Deise Luiza Ferraz procurou fazer ao criticar o conceito de sequestro da subjetividade e o que tentei comentar aqui ao colocar em destaque as críticas e este conceito feitas por ela. Sem críticas não há debates e tampouco há avanços e desenvolvimento das teorias. A crítica é o fundamento do desenvolvimento da ciência.

\section{REFERÊNCIAS}

FARIA, J. H. de. O Autoritarismo nas organizações. Curitiba: Criar, 1985.

FARIA, J. H. de. Crise do autoritarismo e movimentos operários no ABC paulista: 19781980. Revista do IMESC, v. 3, n.7, p. 16-31, 1985 b.

FARIA, J. H. de. Tecnologia e processo de trabalho. Curitiba: Editora da UFPR, 1992. FARIA, José Henrique de. Economia política do poder. Curitiba: Juruá, 2004. 3 Volumes. FARIA, J. H. de. Poder, controle e gestão. Curitiba: Juruá, 2017.

FARIA, J. H. de.; MENEGHETTI, F. K.. O Sequestro da Subjetividade. In: FARIA, J. H. Análise crítica das teorias e práticas organizacionais. São Paulo: Atlas, 2007, p. 45-67. KOSIK, K. Dialética do concreto. Rio de Janeiro: Paz e Terra, 1976.

MARX, K. O Capital: crítica da economia política. Livro I. São Paulo: Boitempo Editorial, 2013. Posfácio da Segunda Edição. 